\title{
Häufig bakterielle Koinfektionen
}

Centers for Disease Control and Prevention. Bacterial Coinfections in Lung Tissue Specimens from Fatal Cases of 2009 Pandemic Influenza $A\left(\mathrm{H}_{1} \mathrm{~N}_{1}\right)$ - United States, May-August 2009. MMWR 2009;58:1071-1074

\section{Hintergrund und Fragestellung}

Von vorhergehenden Influenzapandemien ist bekannt, dass die meisten verstorbenen Patienten, für deren Tod eine Influenza-A-Infektion verantwortlich gemacht wurde, gleichzeitig eine bakterielle Pneumonie hatten. Es stellt sich daher die Frage, ob das auch für die aktuelle H1N1-Influenza-A-Pandemie gilt.

\section{Methodik}

Die Centers for Disease Control and Prevention (CDC) untersuchten postmortales Lungengewebe von 77 USamerikanischen Patienten, die zwischen Mai und August 2009 an einer H1N1Infektion verstorben sind, auf bakterielle Erreger.

\section{Ergebnisse}

Eine gleichzeitige bakterielle Infektion fand sich bei 22 (29\%) der 77 Patienten. Zehn dieser Infektionen waren durch Streptococcus pneumoniae (Pneumokokken) verursacht. Die Dauer der Erkrankung betrug im Median sechs Tage (1-25 Tage). Nur 44\% der verstorbenen Patienten waren hospitalisiert.

\section{Schlussfolgerung}

Diese Daten bestätigen, dass bakterielle Lungeninfektionen bei Patienten mit tödlicher Lungeninfektion durch H1N1 im Jahr 2009 vergleichsweise häufig auftraten.

\section{Kommentar}

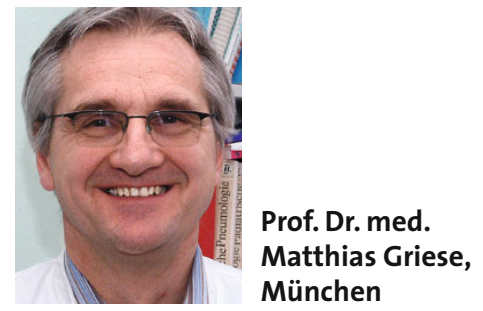

Aus diesen Daten lassen sich drei wichtige Folgerungen ableiten:

1. Die frühe Erkennung bakterieller Infektionen bei Patienten mit Influenza ist wichtig. Gegebenenfalls sollte eine entsprechende antibiotische Behandlung eingeleitet werden.

2. Pneumokokken-Impfung: Sie wird von der STIKO für alle Personen mit erhöhtem Risiko für Pneumokokken-Pneumonien empfohlen. Die Impfung mit einem Konjugatimpfstoff gehört zum RoutineImpfprogramm für Kinder ab dem vollendeten zweiten Lebensmonat. Der 23valente Polysaccharidimpfstoff wird für alle Personen mit erhöhter gesundheitlicher Gefährdung (z.B. Frühgeburt, chronische Lungenerkrankung etc.) empfohlen, die Impfung mit dem PneumokokkenPolysaccharid-Impfstoff für Patienten $a b$ dem 6o. Lebensjahr. Eine Wiederimpfung sollte im Abstand von sechs Jahren erfolgen.

3. Postmortale Lungenbiopsien: Gerade im Kindesalter bleiben viele unklare Lungenerkrankungen auch heute noch weitgehend ungeklärt. Ursache hierfür sind Obduktionsraten von maximal nur $5 \%$ in Deutschland. Diese Zahlen sind erschreckend niedrig, z.B. im Vergleich zur Schweiz, die eine Obduktionsrate von etwa 20\% aufweist.

Postmortale Biopsien der Lunge können gut durch einen ca. $1 \mathrm{~cm}$ großen Einschnitt in der lateralen Thoraxwand gewonnen und die Wunde mit Nähten verschlossen werden. Dieses Vorgehen wird im Gegensatz zur konventionellen Autopsie, die oft nur schwer akzeptiert wird, von mehr als $80 \%$ der Hinterbliebenen akzeptiert.

Verstorbene, deren Organe nicht für die Transplantation weiterverwendet werden können, sollten zur genauen Klärung der Todesursache obduziert werden. Lässt sich hierfür von den Angehörigen kein Einverständnis erzielen, ist an die Möglichkeit einer postmortalen Biopsie zu denken, die im Falle der Lunge in Form einer kleinen, offenen Lungenbiopsie mit gutem Ergebnis durchgeführt werden kann.

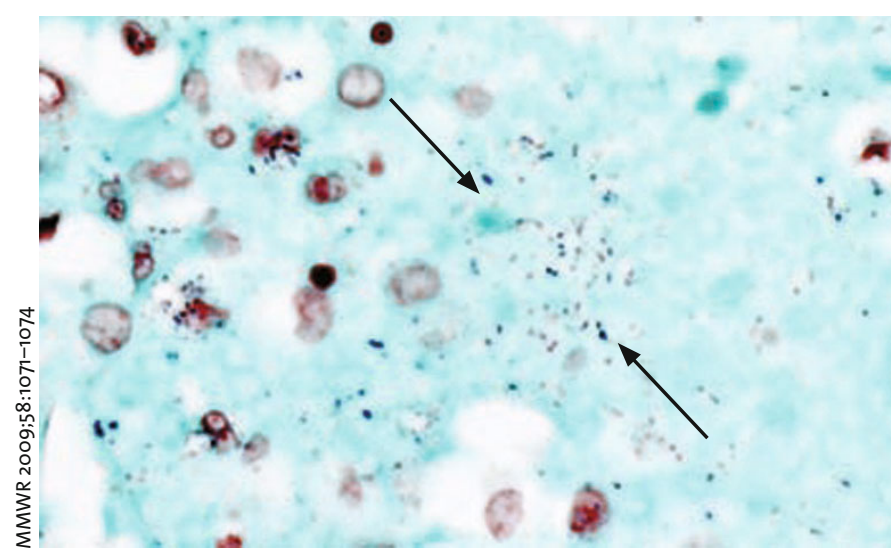

Nachweis grampositiver Kokken im Lungengewebe eines Patienten mit H1N1-Infektion (mittels Lillie-Twort-Gramfärbung).

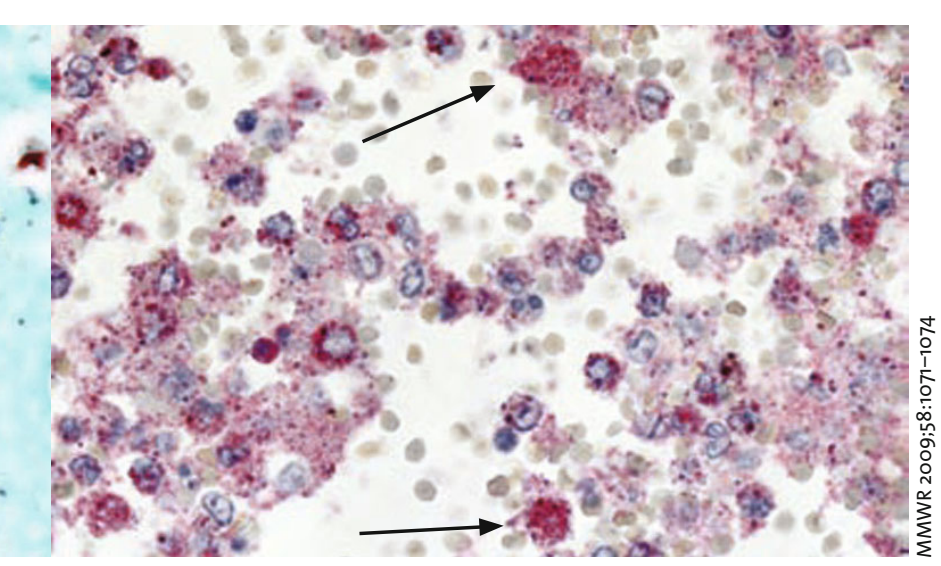

Immunhistochemischer Nachweis von Streptococcus pneumoniae im Lungengewebe eines Patienten mit H1N1-Infektion. 